\title{
Unraveling the Link between Malnutrition and Adverse Clinical Outcomes: Association of Acute and Chronic Malnutrition Measures with Blood Biomarkers from Different Pathophysiological States
}

\author{
Susan Felder ${ }^{\mathrm{a}}$ Nina Braun ${ }^{\mathrm{a}}$ Zeno Stanga ${ }^{\mathrm{d}}$ Prasad Kulkarni $^{\mathrm{e}}$ Lukas Faessler $^{\mathrm{a}}$ \\ Alexander Kutz $^{\mathrm{a}}$ Deborah Steiner ${ }^{\mathrm{a}}$ Svenja Laukemann ${ }^{\mathrm{a}}$ Sebastian Haubitz ${ }^{\mathrm{c}}$ \\ Andreas Huber $^{\mathrm{b}}$ Beat Mueller ${ }^{\mathrm{a}}$ Philipp Schuetz $^{\mathrm{a}}$ \\ a University Department of Internal Medicine and bepartment of Laboratory Medicine, Kantonsspital Aarau, Aarau, \\ 'University Clinic of Infectious Diseases, University Hospital Bern (Inselspital), and d Department of Endocrinology, Diabetes \\ and Clinical Nutrition, University Hospital Bern (Inselspital), Bern, Switzerland; ${ }^{\mathrm{A}}$ Asclepius Medical Communications LLC, \\ Ridgewood, N.J., USA
}

\section{Key Words}

Malnutrition · Outcomes · Biomarker · Hospitalization ·

Nutrition screening

\begin{abstract}
Background and Aims: Malnutrition is associated with poor clinical outcomes. Whether there is a causal relationship or it merely mirrors a severe patient condition remains unclear. We examined the association of malnutrition with biomarkers characteristic of different pathophysiological states to better understand the underlying etiological mechanisms. Methods: We prospectively followed consecutive adult medical inpatients. Multivariable regression models were used to investigate the associations between malnutrition as assessed using the Nutritional Risk Screening (NRS 2002) and biomarkers linked to inflammation, stress, renal dysfunction, nutritional status and hematologic function. $\boldsymbol{R e}$ sults: A total of 529 patients were included. In a fully adjusted model, malnutrition was significantly associated
\end{abstract}

\section{KARGER}

E-Mail karger@karger.com

www.karger.com/anm with the inflammatory markers procalcitonin $(0.20,95 \% \mathrm{Cl}$ $0.03-0.37)$, proadrenomedullin $(0.28,95 \% \mathrm{Cl} 0.12-0.43)$ and albumin $(-0.39,95 \% \mathrm{Cl}-0.57$ to -0.21$)$, the stress marker copeptin $(0.34,95 \% \mathrm{Cl} 0.17-0.51)$, the renal function marker urea $(0.23,95 \% \mathrm{Cl} 0.07-0.38)$, the nutritional markers vitamin D25 $(-0.22,95 \% \mathrm{Cl}-0.41$ to -0.02$)$ and corrected calcium $(0.29,95 \% \mathrm{Cl} 0.10-0.49)$ and the hematological markers hemoglobin $(-0.27,95 \% \mathrm{Cl}-0.43$ to -0.10$)$ and red blood cell distribution width $(0.26,95 \% \mathrm{Cl} 0.07-0.44)$. Subgroup analysis suggested that acute malnutrition rather than chronic malnutrition was associated with elevated biomarker levels. Conclusion: Acute malnutrition was associated with a pronounced inflammatory response and an alteration in biomarkers associated with different pathophysiological states. Interventional trials are needed to prove causality.

(c) 2016 S. Karger AG, Basel
(C) 2016 S. Karger AG, Basel

0250-6807/16/0683-0164\$39.50/0
Prof. Philipp Schuetz, MD, MPH

University Department of Internal Medicine

Kantonsspital Aarau, Tellstrasse

CH-5001 Aarau (Switzerland)

E-Mail schuetzph@gmail.com 


\section{Introduction}

Malnutrition is a frequent problem in hospitalized medical patients and may result from chronic diseases, which lead to cachexia and weight loss, or acute illness, which decreases appetite and nutritional intake. Approximately $30 \%$ of patients hospitalized on medical wards are at risk nutritionally, with available evidence suggesting that these patients have poorer clinical outcomes exemplified by higher rates of morbidity and mortality as well as prolonged hospital stays $[1,2]$. There is thus a clear need for proactive screening and management of malnutrition in the hospital setting. Screening for malnutrition in adult inpatients is best accomplished following the $\mathrm{Nu}$ tritional Risk Screening (NRS) 2002 guidelines published by the European Society for Clinical Nutrition and Metabolism (ESPEN) [3]. These guidelines permit the categorization of a patient's impaired nutritional status taking into consideration the severity of disease.

Despite the high prevalence of malnutrition in the hospital setting, the underlying pathophysiologic mechanisms and their impact on laboratory findings are still incompletely understood $[4,5]$. Earlier studies in this area attribute a central role for cytokines in the pathogenesis of cachexia, particularly cancer cachexia. Cytokines are an integral part of the systemic inflammatory response and have been implicated in the etiology of anorexia, weight loss, cognitive dysfunction, anemia and frailty. They induce ubiquitin-mediated proteolysis that releases amino acids, which are then used for the hepatic production of C-reactive protein (CRP) [6]. Cytokines are also implicated in an imbalance of stress hormones, with increased glucocorticoid hormones and decreased sexual hormones potentially contributing to catabolism [7]. Furthermore, recent studies have suggested the occurrence of cross talk between inflammatory cytokines and glucagon-like peptide-1 (GLP-1), reducing food intake and inducing weight loss [8]. These diverse pathways are thought to synergistically play a role in (cancer) cachexia, which has been characterized by the ESPEN as a systemic pro-inflammatory process that results in metabolic derangements that include insulin resistance, loss of body fat and muscle and increased lipolysis, lipid oxidation, protein turnover and production of acute phase proteins [9].

Inflammation in acutely and chronically ill patients is thought to influence nutritional status. Conversely, dietary factors also have an impact on the inflammatory response and clinical outcomes. This bidirectional relationship is complex and currently incompletely under- stood. Whether malnutrition has a direct link to adverse outcomes or is instead a mirror of disease severity remains unclear. Herein, our aim was to study whether acute and chronic malnutrition as assessed with the NRS 2002 is associated with blood biomarkers of inflammation/infection, stress and kidney and hematological function. We also investigated whether these associations remained robust after rigorous adjustment for disease severity and other potential confounding factors in multivariate regression models.

\section{Methods}

\section{Study Design}

This secondary observational analysis included consecutive medical inpatients hospitalized through the emergency department (ED) of a Swiss tertiary care hospital between February 2013 and October 2013. All patients were participants in a prospective, observational, multicenter, multinational trial called the TRIAGE project that aimed to devise an algorithm to optimize triage and anticipate the post-acute care needs of adult patients with medical emergencies [10]. The institutional review board waived the need for informed consent because of the observational nature of the study (through notification EK 2012/059).

\section{Patient Population and Management of Patients}

We used patient data from the TRIAGE project cohort hospitalized during the defined time period (3,585 patients). Five hundred twenty-nine of these patients met inclusion criteria, which included manifest or imminent risk of development of malnutrition as well as availability of NRS scores and all laboratory values. Data on main diagnosis of each patient and left over blood samples were collected from the ED. During their hospital stay, the patients' clinical information including their sociodemographic data was collected, and comorbidities were assessed prospectively. Nursing staff assessed nutritional status using NRS 2002 guidelines within $48 \mathrm{~h}$ after hospital admission.

\section{Definitions of Main Diagnosis and Comorbidities}

The main diagnosis was assigned to different groups using diagnosis-related group codes. Generated groups included infectious diseases, tumors, cardiovascular disease, pulmonary disease, gastrointestinal disease, immune disorders, endocrine disorders, neurological disorders, psychological disorders/intoxication, musculoskeletal disorders and 'other' main diagnoses. Comorbidities were also grouped in a similar manner.

\section{Outcome Measures}

The end point in this study was the association of NRS scores with biomarkers associated with different pathophysiological states. At the time of admission, we measured CRP, procalcitonin (PCT), white blood cell (WBC) count, albumin and proadrenomedullin (proADM) to reflect inflammatory or infectious processes; copeptin as a stress marker; creatinine and urea as indicators of renal function; vitamin D25, corrected calcium and glucose as nutritional markers; and platelets, international normalized ratio 
(INR), hemoglobin and red blood cell distribution width (RDW) as indicators of hematological function.

The following markers were measured as part of routine care: CRP (normal value $\leq 0.3 \mathrm{mg} / \mathrm{l}$ ), WBC (normal range 4.0 $10.0 \times 10^{9} / \mathrm{l}$ ), albumin (normal range 34.0-50.0 g/l), creatinine (normal range 71.0-115.0 $\mathrm{mol} / \mathrm{l}$ ), urea (normal range 2.0-7.0 $\mathrm{mmol} / \mathrm{l}), 25(\mathrm{OH})$ vitamin $\mathrm{D}$ (normal range $50.0-250.0 \mathrm{nmol} / \mathrm{l}$ ), corrected calcium (normal range 2.15-2.55 mmol/l), glucose (normal range [fasting] 3.9-5.5 mmol/l), platelet counts (normal range $140-400 / \mathrm{mm}^{3}$ ), INR (normal range $2.0-3.5$ ), hemoglobin (normal range 135.0-172.0 g/l) and RDW (normal range $\leq 15.0 \%)$.

In addition, we measured PCT levels post hoc using an automated rapid sensitive assay (the KRYPTOR PCT assay produced by Thermo Scientific Biomarkers (formerly B.R.A.H.M.S AG), Hennigsdorf, Germany; normal range $\leq 0.50 \mu \mathrm{g} / \mathrm{l}$ and detection limit $0.02 \mu \mathrm{g} / \mathrm{l})$. Concentrations of ProADM were batch-measured in plasma using an automated sandwich chemiluminescence immunoassay on the KRYPTOR system (detection limit $0.05 \mathrm{nmol} / \mathrm{l}$ ). Copeptin (normal range $<19.0 \mathrm{pmol} / \mathrm{l}$ and detection limit 0.9 $\mathrm{pmol} / \mathrm{l}$ ) was detected in stored EDTA plasma samples of all patients with a new sandwich immunoassay (B.R.A.H.M.S Sevapres$\sin ^{\circledR}$ LIA, B.R.A.H.M.S AG, Hennigsdorf, Germany).

Assessment of Nutritional Status and Definition of Nutritional Impairment

Nutritional status was assessed using the NRS 2002, a screening tool that considers nutritional status (1-3 points), severity of illness (1-3 points) and age (one point if age $>70$ years). As recommended in the original publication by Kondrup et al. [11], a NRS score $\geq 3$ was designated as a cutoff for malnutrition or risk of developing malnutrition. The NRS score includes measures of both acute (reduced food intake during the last week) and chronic (low BMI, indicative of weight loss over a 3-month period) malnutrition. In recognition of this, we classified malnutrition seen in the patients in this study as being acute or chronic.

\section{Statistical Analysis}

The association between NRS scores and biomarker levels was assessed with patients being categorized into 3 groups based on NRS scores: NRS $<3$, NRS $=3$ and NRS $>3$. Patient characteristic variables are expressed as medians (interquartile ranges [IQR; 25th-75th percentiles]), while frequencies are reported as percentages. Patient characteristics were compared using the chi-square test for binary data and analysis of variance for continuous data across the 3 NRS groups. Biomarker levels are graphically depicted in figure 1. For ease of comparison during further analyses, laboratory values were transformed into deciles. The association between NRS scores and laboratory findings was explored using linear regression analyses, with results being reported as coefficients with 95\% CIs. Additionally, we adjusted for age and gender (Model 1); age, gender and comorbidities (Model 2); and age, gender, comorbidities and main diagnosis (Model 3). Furthermore, we conducted a subgroup analysis in which acutely and chronically malnourished patients were studied separately. Patients with concomitant acute malnutrition and chronic weight loss were excluded from the subgroup analyses. All statistical analyses were performed using the STATA 12.1 software package (StataCorp, College Station, Tex., USA). A p value $<0.05$ (for a 2 -sided test) was considered statistically significant.

\section{Results}

\section{Patient Population}

Of 529 patients meeting the inclusion criteria, 350 (66.2\%) had no nutritional impairment, while 179 (33.8\%) were nutritionally at risk, with NRS scores of 3 points $(91,17.2 \%)$ or higher $(88,16.6 \%)$. Baseline characteristics of the study cohort according to NRS score are shown in table 1 . Two hundred twenty-seven (42.9\%) patients were women, and their median age was 72 years (IQR 62-80). Patients at risk nutritionally were significantly older (ages 69 vs. 73 vs. 73 years for patients with NRS scores less than, equal to or greater than 3 , respectively; $\mathrm{p}<0.001$ ) and suffered more often from tumors and gastrointestinal diseases but less often from cardiovascular diseases.

\section{Laboratory Findings}

Patients at risk nutritionally showed significantly higher CRP levels (70.6 vs. 83.4 vs. $103.5 \mathrm{mg} / \mathrm{l}, \mathrm{p}=0.027$ ), PCT levels (0.16 vs. 0.21 vs. $0.24 \mu \mathrm{g} / \mathrm{l}, \mathrm{p}=0.007)$ and proADM levels ( 1.34 vs. 1.62 vs. $1.62 \mathrm{nmol} / \mathrm{l}, \mathrm{p}=0.001)$. There was no significant difference in WBC counts between the 3 groups ( 10.31 vs. 9.66 vs. $10.61 \times 10^{9} / 1, \mathrm{p}=$ 0.54 ). Albumin was lower in patients nutritionally at risk (33.4 vs. 31.4 vs. 28.9 g/l, p < 0.001). Copeptin, a stress marker, was present at higher levels in these patients (24.7 vs. 40.0 vs. $53.5 \mathrm{pmol} / \mathrm{l}, \mathrm{p}<0.001)$. Renal function differed as measured by urea levels ( 6.6 vs. 7.9 vs. $8.0 \mathrm{mmol} / \mathrm{l}, \mathrm{p}=$ 0.036 ), but not in terms of creatinine levels ( 99.0 vs. 97.0 vs. $95.5 \mu \mathrm{mol} / \mathrm{l}, \mathrm{p}=0.530)$. Surprisingly, corrected calcium was present at higher levels in malnourished patients ( 2.33 vs. 2.39 vs. $2.42 \mathrm{mmol} / \mathrm{l}, \mathrm{p}<0.001$ ), while both glucose (6.7 vs. 6.7 vs. $6.6 \mathrm{mmol} / \mathrm{l}, \mathrm{p}=0.870)$ and vitamin D25 (43.3 vs. 32.6 vs. $36.3 \mathrm{nmol} / \mathrm{l}, \mathrm{p}=0.060$ ) showed no significant aberrations. Hemoglobin was significantly lower ( 128.5 vs. 122.0 vs. $117.5 \mathrm{~g} / \mathrm{l}, \mathrm{p}<0.001)$ and RDW was significantly higher ( 14.0 vs. 15.3 vs. $15.0 \%, p<0.001)$ in patients with NRS scores $\geq 3$. Patients' platelet counts or INR values did not differ significantly between the 3 groups. Laboratory findings (median and 75th percentile) of the 3 patient groups are visually represented in figure 1 .

\section{Association of NRS Scores with Biomarker Levels}

We performed linear regression analyses (regression coefficient, 95\% CI, $\mathrm{p}$ value) and found a stepwise increase of inflammation/infection biomarkers (CRP 0.21, 95\% CI 0.03-0.39, $\mathrm{p}=0.021$; PCT $0.28,95 \%$ CI 0.10-0.47, $\mathrm{p}=0.003$; proADM $0.40,95 \%$ CI $0.23-0.58, \mathrm{p}<0.001$; 

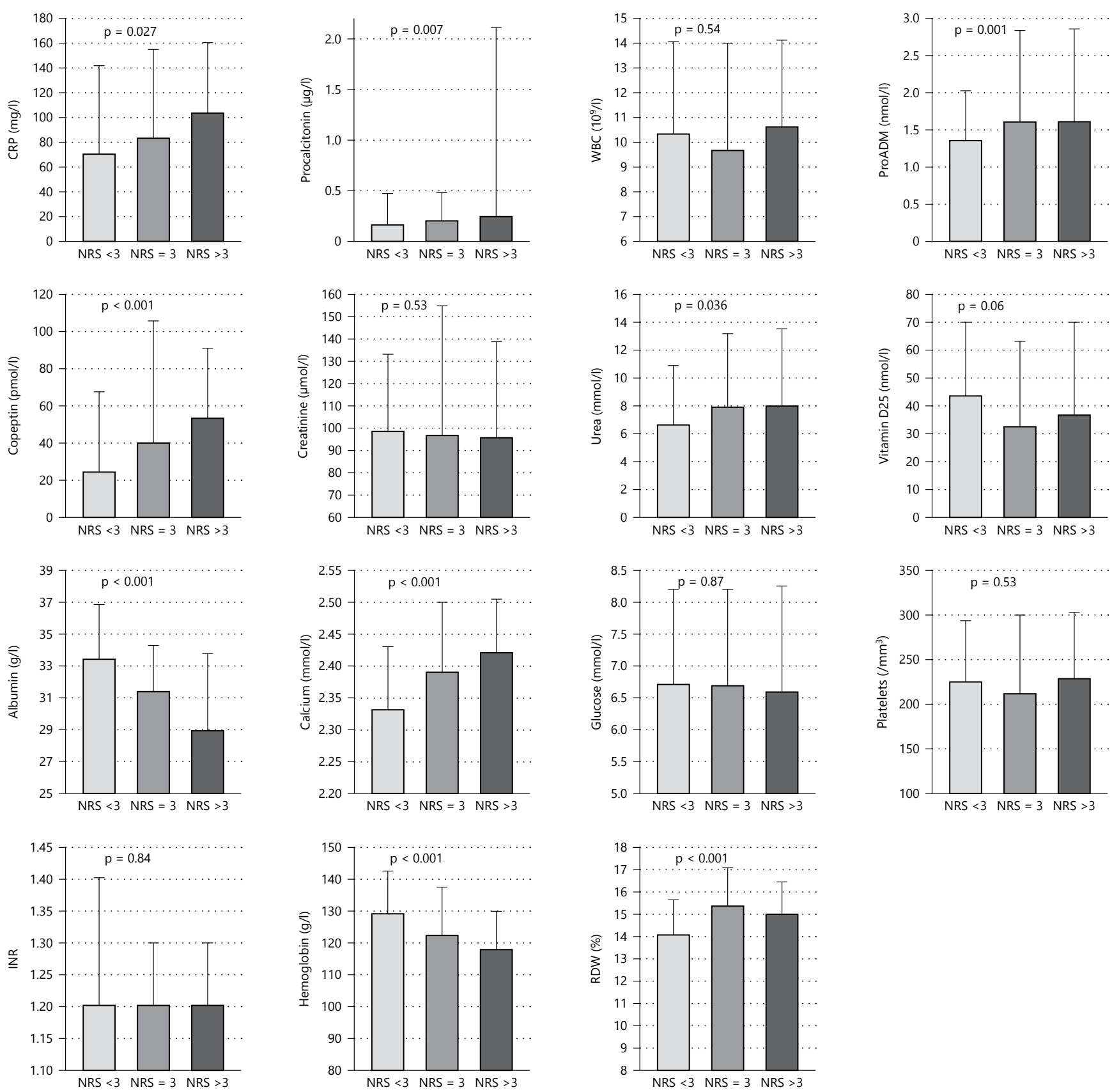

Fig. 1. Median biomarker levels categorized by NRS score (bars represent medians and error bars identify the 75 th percentile).

albumin $-0.60,95 \% \mathrm{CI}-0.77$ to $-0.43, \mathrm{p}<0.001)$ in patients with NRS scores $<3,3$ and $>3$ points, with the exception of WBC counts $(-0.04,95 \%$ CI -0.22 to $0.14, \mathrm{p}=$ $0.630)$. Higher NRS scores were also associated with higher copeptin $(0.44,95 \%$ CI $0.27-0.62, \mathrm{p}<0.001)$ and urea $(0.28,95 \%$ CI $0.10-0.46, \mathrm{p}=0.002)$ levels. Findings were similar with regard to lower levels of vitamin D25 $(-0.23,95 \% \mathrm{CI}-0.41$ to $-0.05, \mathrm{p}=0.012)$ as well as higher levels of corrected calcium $(0.43,95 \%$ CI $0.26-0.61$, $\mathrm{p}<0.001)$. No significant association was found for glu- 
Table 1. Patient characteristics categorized by NRS scores

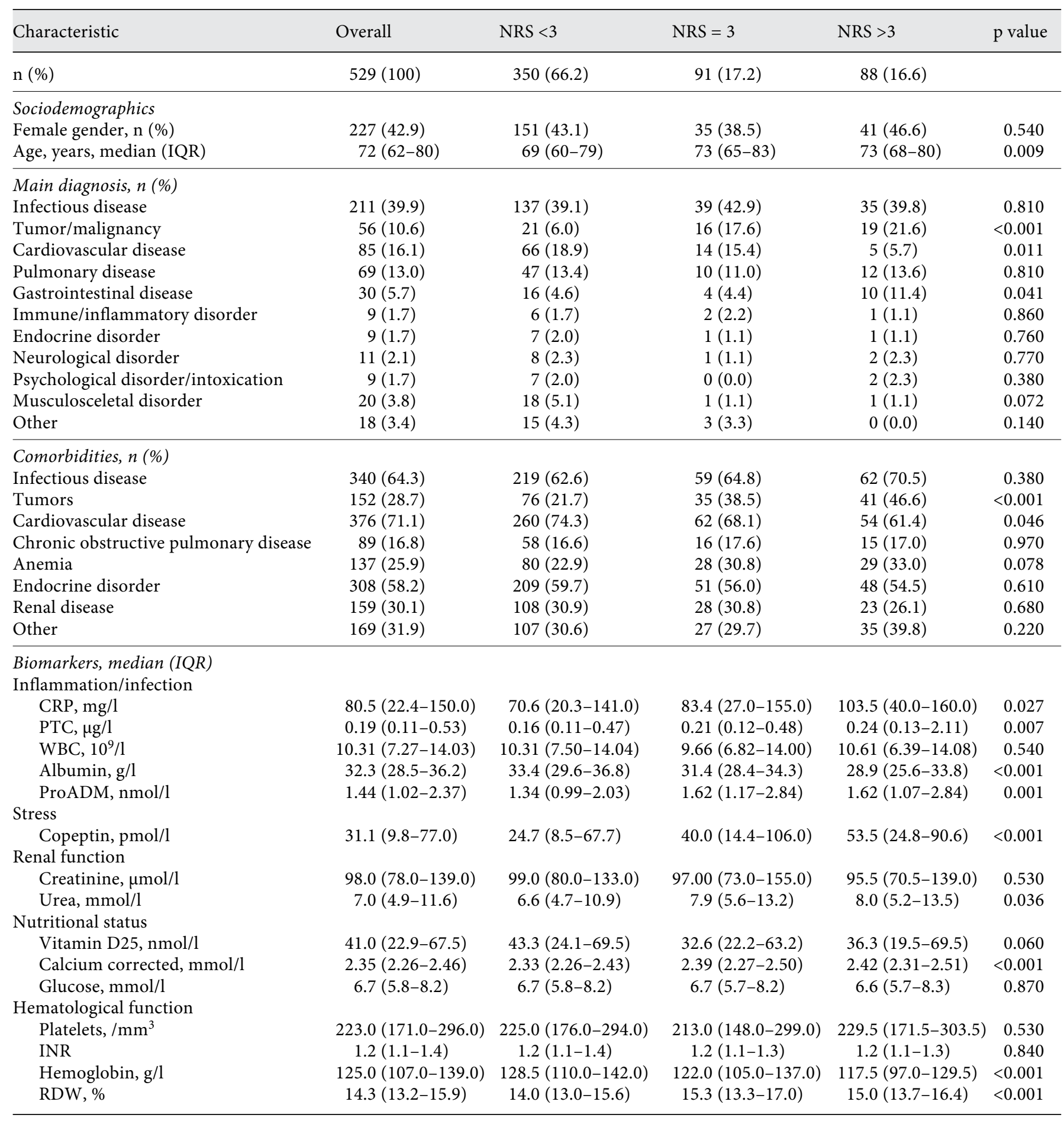


Table 2. Association between NRS scores and biomarkers (transformed into deciles), adjusted for age/gender (Model 1), age/gender/ comorbidities (Model 2) and age/gender/comorbidities/main diagnosis (Model 3)

\begin{tabular}{|c|c|c|c|c|c|c|c|c|}
\hline & \multicolumn{2}{|l|}{ Unadjusted } & \multicolumn{2}{|l|}{ Model 1} & \multicolumn{2}{|l|}{ Model 2} & \multicolumn{2}{|l|}{ Model 3} \\
\hline & coefficient $(95 \% \mathrm{CI})$ & $\mathrm{p}$ value & coefficient $(95 \% \mathrm{CI})$ & $\mathrm{p}$ value & coefficient $(95 \% \mathrm{CI})$ & $\mathrm{p}$ value & coefficient $(95 \% \mathrm{CI})$ & $\mathrm{p}$ value \\
\hline \multicolumn{9}{|l|}{ Inflammation/infection } \\
\hline $\mathrm{CRP}, \mathrm{mg} / \mathrm{l}$ & $0.21(0.03$ to 0.39$)$ & 0.021 & $0.26(0.07$ to 0.44$)$ & 0.006 & $0.13(-0.06$ to 0.31$)$ & 0.179 & $0.13(-0.05$ to 0.31$)$ & 0.171 \\
\hline PCT, $\mu \mathrm{g} / \mathrm{l}$ & $0.28(0.10$ to 0.47$)$ & 0.003 & $0.27(0.08$ to 0.46$)$ & 0.005 & $0.18(0.00$ to 0.36$)$ & 0.050 & $0.20(0.03$ to 0.37$)$ & 0.025 \\
\hline WBC, $10^{9} / 1$ & $-0.04(-0.22$ to 0.14$)$ & 0.630 & $-0.05(-0.24$ to 0.13$)$ & 0.567 & $0.02(-0.17$ to 0.22$)$ & 0.808 & $0.01(-0.19$ to 0.21$)$ & 0.923 \\
\hline Albumin, $\mathrm{g} / \mathrm{l}$ & $-0.60(-0.77$ to -0.43$)$ & $<0.001$ & $-0.59(-0.76$ to -0.41$)$ & $<0.001$ & $-0.45(-0.63$ to -0.27$)$ & $<0.001$ & $-0.39(-0.57$ to -0.21$)$ & $<0.001$ \\
\hline ProADM, nmol/l & $0.40(0.23$ to 0.58$)$ & $<0.001$ & $0.26(0.09$ to 0.43$)$ & 0.003 & $0.25(0.09$ to 0.40$)$ & 0.002 & $0.28(0.12$ to 0.43$)$ & 0.001 \\
\hline \multicolumn{9}{|l|}{ Stress } \\
\hline Copeptin, pmol/l & $0.44(0.27$ to 0.62$)$ & $<0.001$ & $0.28(0.11$ to 0.45$)$ & 0.001 & $0.31(0.14$ to 0.48$)$ & $<0.001$ & $0.34(0.17$ to 0.51$)$ & $<0.001$ \\
\hline \multicolumn{9}{|l|}{ Renal function } \\
\hline Creatinine, $\mu \mathrm{mol} / \mathrm{l}$ & $-0.04(-0.22$ to 0.14$)$ & 0.653 & $-0.15(-0.33$ to 0.03$)$ & 0.094 & $-0.03(-0.18$ to 0.12$)$ & 0.693 & $0.02(-0.12$ to 0.16$)$ & 0.791 \\
\hline Urea, $\mathrm{mmol} / \mathrm{l}$ & $0.28(0.10$ to 0.46$)$ & 0.002 & $0.11(-0.06$ to 0.29$)$ & 0.197 & $0.19(0.04$ to 0.35$)$ & 0.013 & $0.23(0.07$ to 0.38$)$ & 0.004 \\
\hline \multicolumn{9}{|l|}{ Nutritional status } \\
\hline Vitamin D25, nmol/l & $-0.23(-0.41$ to -0.05$)$ & 0.012 & $-0.19(-0.37$ to 0.00$)$ & 0.046 & $-0.22(-0.41$ to -0.02$)$ & 0.027 & $-0.22(-0.41$ to -0.02$)$ & 0.031 \\
\hline Calcium, corrected, $\mathrm{mmol} / \mathrm{l}$ & $0.43(0.26$ to 0.61$)$ & $<0.001$ & $0.40(0.22$ to 0.59$)$ & $<0.001$ & $0.32(0.13$ to 0.51$)$ & 0.001 & $0.29(0.10$ to 0.49$)$ & 0.002 \\
\hline Glucose, $\mathrm{mmol} / \mathrm{l}$ & $-0.02(-0.20$ to 0.16$)$ & 0.796 & $-0.09(-0.28$ to 0.09$)$ & 0.312 & $-0.08(-0.27$ to 0.10$)$ & 0.380 & $-0.07(-0.26$ to 0.12$)$ & 0.454 \\
\hline \multicolumn{9}{|l|}{ Hematological function } \\
\hline Platelets, $/ \mathrm{mm}^{3}$ & $-0.06(-0.24$ to 0.12$)$ & 0.506 & $-0.09(-0.27$ to 0.10$)$ & 0.354 & $-0.07(-0.26$ to 0.12$)$ & 0.489 & $-0.08(-0.28$ to 0.11$)$ & 0.403 \\
\hline INR & $0.15(-0.05$ to 0.35$)$ & 0.143 & $0.06(-0.14$ to 0.26$)$ & 0.568 & $0.14(-0.07$ to 0.35$)$ & 0.194 & $0.13(-0.08$ to 0.34$)$ & 0.222 \\
\hline Hemoglobin, g/l & $-0.50(-0.67$ to -0.32$)$ & $<0.001$ & $-0.48(-0.66$ to -0.30$)$ & $<0.001$ & $-0.29(-0.45$ to -0.12$)$ & 0.001 & $-0.27(-0.43$ to -0.10$)$ & 0.002 \\
\hline RDW, \% & $0.46(0.28$ to 0.63$)$ & $<0.001$ & $0.40(0.22$ to 0.58$)$ & $<0.001$ & $0.28(0.10$ to 0.46$)$ & 0.003 & $0.26(0.07$ to 0.44$)$ & 0.006 \\
\hline
\end{tabular}

Bold values denote significant results.

cose levels $(-0.02,95 \%$ CI -0.20 to $0.16, \mathrm{p}=0.796)$. As far as hematological parameters were concerned, there was a significant correlation between nutritional risk and hemoglobin levels $(-0.50,95 \%$ CI -0.67 to $-0.32, \mathrm{p}<0.001)$ as well as RDW $(0.46,95 \%$ CI $0.28-0.63, \mathrm{p}<0.001)$. Hemostatic parameters, namely platelet counts $(-0.06,95 \%$ CI -0.24 to $0.12, \mathrm{p}=0.506)$ and $\operatorname{INR}(0.15,95 \% \mathrm{CI}-0.05$ to $0.35, \mathrm{p}=0.143$ ), were not significantly associated with the NRS score. After stepwise adjustment for demographics (Model 1), comorbidities (Model 2) and main diagnosis (Model 3), these associations remained robust. Only CRP levels ceased to be significantly correlated with NRS scores after adjustment for comorbidities $(0.13$, $95 \%$ CI -0.06 to $0.31, p=0.179)$. Levels of PCT showed marginal insignificance in Model 2 (0.18, 95\% CI 0.00$0.36, \mathrm{p}=0.050)$ but regained significance in Model 3 $(0.20,95 \%$ CI $0.03-0.37, \mathrm{p}=0.025)$. Detailed results are displayed in table 2 .

\section{Association of Acute and Chronic Malnutrition with \\ Biomarker Levels}

Subgroup analyses revealed that only acutely malnourished patients had significant associations between nutritional risk and CRP levels $(0.92,95 \%$ CI $0.18-1.67$, $\mathrm{p}=0.015)$, proADM $(0.88,95 \%$ CI $0.14-1.62, \mathrm{p}=0.021)$, copeptin $(0.84,95 \%$ CI $0.10-1.59, \mathrm{p}=0.027)$, creatinine
(0.91, 95\% CI 0.17-1.66, $\mathrm{p}=0.016)$, vitamin D25 $(-0.87$, $95 \% \mathrm{CI}-1.61$ to $-0.12, \mathrm{p}=0.022)$ and glucose $(0.81,95 \%$ CI $0.07-1.55, \mathrm{p}=0.033)$. Patients with chronic impairment of nutritional status showed no significant associations with biomarkers of inflammation/infection, renal function, stress or nutritional status. Only 2 parameters of hematological function, platelets $(1.13,95 \%$ CI $0.32-$ $1.95, \mathrm{p}=0.006)$ and RDW (0.88, 95\% CI 0.06-1.70, $\mathrm{p}=$ 0.036 ) were significantly associated with NRS scores in these patients. Detailed results are presented in table 3.

\section{Discussion}

We found strong associations between nutritional status and biomarkers from multiple pathophysiological states, including inflammation/infection, stress and kidney and hematological function. Compared within the different NRS score categories, patients at risk nutritionally had more pronounced alterations of biomarker levels. This was confirmed through linear regression analyses adjusted for different confounding factors. Although observational studies may not prove causality, our results support the hypothesis that the adverse outcomes often seen in malnourished patients are linked through these pathways. 
Table 3. Association between NRS scores and biomarkers (transformed into deciles); subgroup analysis of acute vs. chronic malnutrition

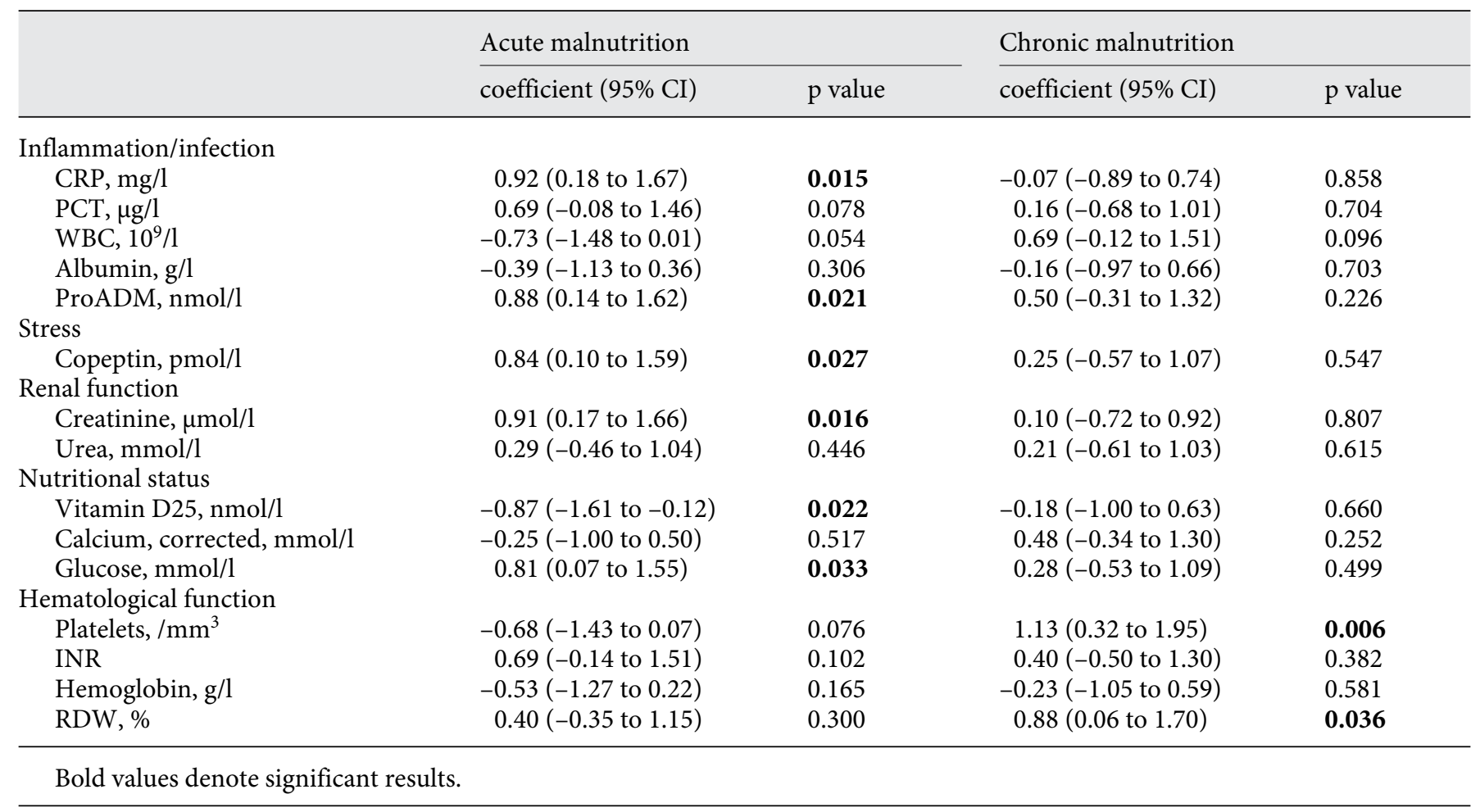

To evaluate the risk for malnutrition, we used the NRS 2002, a screening tool whose use has shed light on adverse clinical outcomes associated with malnutrition across multiple patient populations [11]. We also asked the question as to which among acute and chronic malnutrition had stronger associations with adverse outcomes. We found the association to be stronger with acute malnutrition, defined as reduced nutritional intake within the last 7 days. An International Consensus Guideline Committee constituted to develop a consensus approach to defining malnutrition syndromes for adults in the clinical setting proposed an etiology-based definition of malnutrition [12]. The Academy of Nutrition and Dietetics and the American Society for Parenteral and Enteral Nutrition therefore introduced 3 malnutrition categories based on underlying cause, with the categories including malnutrition in the context of (a) social and environmental circumstances, (b) chronic illness and (c) acute illness or injury [13]. Our results showing differences in biomarker levels in patients with acute versus chronic malnutrition support these definition categories and suggest that different pathophysiological pathways are activated in each of these categories. This is especially true in the case of markers of inflammation, which reflect moderate in- flammatory reactions in chronically ill patients and a strongly activated inflammatory system in acutely ill patients. Whether these findings also have therapeutic implications remains to be investigated in interventional trials.

\section{Perspectives from Other Studies}

Multiple studies have reported an association between nutritional impairment and inflammation as measured using CRP levels. Earlier studies have found that malnutrition as assessed by the patient-generated subjective global assessment $[14,15]$ and the Mini-Nutritional Assessment and weight loss [16] was associated with higher levels of CRP. However, the methods used to assess nutritional status differed from those in our study. Our study confirms this association using another screening tool (NRS 2002) and looking at additional biomarkers of inflammation such as PCT and proADM. Importantly, the multivariate models revealed that the association between NRS scores and CRP was no longer significant, which suggests that CRP is mainly influenced by disease severity and age, and that malnutrition per se affects it to a lesser extent.

To our knowledge, this is the first report evaluating the association between NRS scores and copeptin, a marker 
of stress [17]. Copeptin is part of pre-pro-vasopressin, a precursor of vasopressin, and is influenced by volume, osmotic and stress stimuli. Of note, we did not assess flu$\mathrm{id} /$ volume status in our cohort and therefore could not differentiate which stimulus may have been most important in increasing copeptin levels in patients with elevated NRS scores [18].

A study conducted by Tufan et al. [19] found that in addition to routinely used markers of malnutrition, the urea/creatinine ratio may provide additional information on malnutrition in a population of hemodialysis patients. Our findings indicating significant association of malnutrition with urea but not with creatinine support that hypothesis. However, the increase in urea may well be a sign of protein catabolism in these malnourished patients.

Specific nutritional markers would be very important in improving malnutrition screening. Much attention has been paid to albumin levels as a putative nutritional marker. Historically, albumin was considered as a nutritional marker because of its decrease in patients with severe protein malnutrition and Kwashiorkor, but today the association between malnutrition and albumin is questioned, with albumin being viewed instead as a negative acute phase protein [20], for which reason we have included albumin with the markers of inflammation.

In regard to lower hemoglobin levels, the higher prevalence of anemia in malnourished patients is in line with previous research and may be partly explained by the inflammatory reaction and by decreased production of hemoglobin due to low substrate levels [21].

\section{Methodological Aspects}

A strength of the present study is the number of clinical biomarkers associated with different pathophysiological states that were evaluated. An additional strength is the use of the NRS 2002 as a screening tool. The NRS 2002 is an evidence-based and extensively used screening tool that has been validated and is recommended by the ESPEN as being suitable for use in screening adult inpatients $[3,20]$.

Our study has some limitations. First, the heterogeneity of patients suffering from acute or chronic malnutrition introduces significant variability into the statistical models. Second, we used NRS 2002 as a surrogate for malnutrition but performed no further detailed assessments of nutritional status. The NRS 2002 is a nutritional screening tool and not all patients with increased risk as assessed by the NRS may have clinical malnutrition. Third, we only assessed initial biomarker levels; whether biomarker

Unraveling the Link between Malnutrition and Adverse Clinical Outcomes kinetics are influenced by malnutrition status or disease severity remains unclear. Finally, this study does not prove causality between malnutrition and biomarker levels despite adjustment for different potentially confounding factors. This relationship should be investigated in further interventional studies exploring the effect of nutritional therapy on biomarkers.

\section{Clinical Implications}

Our study revealed that increasing age and malignancies were significantly associated with malnutrition whether they were primary diagnoses or comorbidities. This finding, combined with the knowledge of the number of elderly patients or patients with tumors who are hospitalized will enable a more accurate estimation of the true burden of malnutrition in hospitalized patients than is currently available. Awareness of the true burden of malnutrition in this patient population may prompt proactive assessment of nutritional status immediately upon admission and thereby facilitate the timely implementation of interventions to address malnutrition in patients at risk (e.g. the elderly or those with tumors).

Combining patient history with information on the levels of biomarkers shown to be significantly associated with malnutrition in our study (e.g. CRP, PCT, proADM, copeptin, albumin, corrected calcium, hemoglobin, and RDW) may assist with risk stratification, early identification of patients at risk for malnutrition, timely institution of appropriate interventions and follow-up of responses to these interventions. Given that levels of many of these biomarkers are routinely assessed at admission or can be obtained without too much difficulty, assessment of nutritional status should not prove to be a significant problem. Interventions to address nutritional deficiencies have the potential to significantly improve clinical outcomes through their possible impact on lengths of stay, readmission rates and mortality. Future studies exploring the impact of proactive assessment of nutritional status and timely implementation of appropriate interventions on these parameters may be informative [22].

\section{Conclusion}

Acute malnutrition was associated with a pronounced inflammatory response and an alteration in levels of biomarkers associated with different pathophysiological states. Interventional trials are needed to prove causality. 


\section{Statement of Authorship}

S.F., N.B., L.F., A.K., D.S., S.L., S.H., A.H., B.M. and P.S. were involved in the conceptualization and design of the study. S.F., N.B. and P.S. performed all statistical analyses and wrote the first draft of the manuscript. P.K. helped in the interpretation of results and proof read the manuscript for which he was paid with internal funds of the Kantonsspital Aarau. All authors participated in analysis and interpretation of the data, drafted the initial version of the manuscript, reviewed and revised it critically for important intellectual content and read and approved the final version. The corresponding author had full access to all the data used in the study, had final responsibility with regard to the decision to submit the manuscript for publication and takes full responsibility for the completeness and accuracy of the data.

\section{Disclosure Statement}

Drs. P. Schuetz, A. Kutz and B. Mueller have received support from Thermo Fisher Scientific. All other authors declare that they have no competing interests.

\section{Acknowledgments}

This study was supported in part by the Swiss National Science Foundation (SNSF Professorship, PP00P3_150531/1), the Swiss Academy for Medical Sciences (Schweizerische Akademie der Medizinischen Wissenschaften (SAMW)) and internal funds of the Kantonsspital Aarau.

\section{References}

1 Sorensen J, Kondrup J, Prokopowicz J, Schiesser M, Krahenbuhl L, Meier R, et al: EuroOOPS: an international, multicentre study to implement nutritional risk screening and evaluate clinical outcome. Clin Nutr 2008;27:340-349.

2 Lim SL, Ong KC, Chan YH, Loke WC, Ferguson M, Daniels L: Malnutrition and its impact on cost of hospitalization, length of stay, readmission and 3-year mortality. Clin Nutr 2012; 31:345-350.

3 Kondrup J, Allison SP, Elia M, Vellas B, Plauth M; Educational and Clinical Practice Committee, European Society of Parenteral and Enteral Nutrition (ESPEN): ESPEN guidelines for nutrition screening 2002. Clin Nutr 2003;22:415-421.

4 Schuetz P: 'Eat your lunch!' - controversies in the nutrition of the acutely, non-critically ill medical inpatient. Swiss Med Wkly 2015; 145:w14132.

5 Schutz P, Bally M, Stanga Z, Keller U: Loss of appetite in acutely ill medical inpatients: physiological response or therapeutic target? Swiss Med Wkly 2014;144:w13957.

6 Mitch WE, Goldberg AL: Mechanisms of muscle wasting. The role of the ubiquitinproteasome pathway. N Engl J Med 1996;335: 1897-1905.

7 Schuetz P, Muller B: The hypothalamic-pituitary-adrenal axis in critical illness. Endocrinol Metab Clin North Am 2006;35:823838, $x$.

8 Ellingsgaard H, Hauselmann I, Schuler B, Habib AM, Baggio LL, Meier DT, et al: Interleukin-6 enhances insulin secretion by increasing glucagon-like peptide-1 secretion from L cells and alpha cells. Nat Med 2011;17: 1481-1489.
9 Arends J, Bodoky G, Bozzetti F, Fearon K, Muscaritoli M, Selga G, et al: ESPEN guidelines on enteral nutrition: non-surgical oncology. Clin Nutr 2006;25:245-259.

10 Schuetz P, Hausfater P, Amin D, Haubitz S, Fassler L, Grolimund E, et al: Optimizing triage and hospitalization in adult general medical emergency patients: the triage project. BMC Emerg Med 2013;13:12.

11 Kondrup J, Rasmussen $\mathrm{HH}$, Hamberg $\mathrm{O}$, Stanga Z; Ad Hoc ESPEN Working Group: Nutritional risk screening (NRS 2002): a new method based on an analysis of controlled clinical trials. Clin Nutr 2003;22:321-336.

12 Jensen GL, Mirtallo J, Compher C, Dhaliwal R, Forbes A, Grijalba RF, et al: Adult starvation and disease-related malnutrition: a proposal for etiology-based diagnosis in the clinical practice setting from the International Consensus Guideline Committee. JPEN J Parenter Enteral Nutr 2010;34:156159.

13 White JV, Guenter P, Jensen G, Malone A, Schofield M; Academy of Nutrition and Dietetics Malnutrition Work Group; A.S.P.E.N. Malnutrition Task Force; A.S.P.E.N. Board of Directors: Consensus statement of the Academy of Nutrition and Dietetics/American Society for Parenteral and Enteral Nutrition: characteristics recommended for the identification and documentation of adult malnutrition (undernutrition). J Acad Nutr Diet 2012; 112:730-738.

14 Read JA, Choy ST, Beale PJ, Clarke SJ: Evaluation of nutritional and inflammatory status of advanced colorectal cancer patients and its correlation with survival. Nutr Cancer 2006; 55:78-85.
15 Tan CS, Read JA, Phan VH, Beale PJ, Peat JK Clarke SJ: The relationship between nutritional status, inflammatory markers and survival in patients with advanced cancer: a prospective cohort study. Support Care Cancer 2014;23:385-391.

16 Slaviero KA, Read JA, Clarke SJ, Rivory LP: Baseline nutritional assessment in advanced cancer patients receiving palliative chemotherapy. Nutr Cancer 2003;46:148-157.

17 Katan M, Morgenthaler N, Widmer I, Puder JJ, Konig C, Muller B, et al: Copeptin, a stable peptide derived from the vasopressin precursor, correlates with the individual stress level. Neuro Endocrinol Lett 2008;29:341-346.

18 Szinnai G, Morgenthaler NG, Berneis $\mathrm{K}$, Struck J, Muller B, Keller U, et al: Changes in plasma copeptin, the c-terminal portion of arginine vasopressin during water deprivation and excess in healthy subjects. J Clin Endocrinol Metab 2007;92:3973-3978.

19 Tufan F, Yildiz A, Dogan I, Yildiz D, Sevinir $S$ : Urea to creatinine ratio: a forgotten marker of poor nutritional state in patients undergoing hemodialysis treatment. Aging Male 2014; 18:49-53.

20 Fuhrman MP, Charney P, Mueller CM Hepatic proteins and nutrition assessment. J Am Diet Assoc 2004;104:1258-1264.

21 Silva CL, Lima-Costa MF, Firmo JO, Peixoto SV: [Hemoglobin level in older adults and the association with nutritional status and use of health services: the Bambui Project]. Cad Saude Publica 2012;28:2085-2094.

22 Bally MR, Blaser Yildirim PZ, Bounoure L, Gloy VL, Mueller B, Briel M, et al: Nutritional support and outcomes in malnourished medical inpatients: a systematic review and meta-analysis. JAMA Intern Med 2016;176: 43-53. 